\title{
Nutrition intervention strategies to combat zinc deficiency in developing countries
}

\author{
Rosalind S. Gibson and Elaine L. Ferguson \\ Department of Human Nutrition, University of Otago, Dunedin, New Zealand
}

\begin{abstract}
Widespread zinc deficiency is likely to exist in developing countries where staple diets are predominantly plant based and intakes of animal tissues are low. The severe negative consequences of zinc deficiency on human health in developing countries, however, have only recently been recognized. An integrated approach employing targeted supplementation, fortification and dietary strategies must be used to maximize the likelihood of eliminating zinc deficiency at a national level in developing countries. Supplementation is appropriate only for populations whose zinc status must be improved over a relatively short time period, and when requirements cannot be met from habitual dietary sources. As well, the health system must be capable of providing consistent supply, distribution, delivery and consumption of the zinc supplement to the targeted groups. Uncertainties still exist about the type, frequency, and level of supplemental zinc required for prevention and treatment of zinc deficiency. Salts that are readily absorbed and at levels that will not induce antagonistic nutrient interactions must be used. At a national level, fortification with multiple micronutrients could be a cost effective method for improving micronutrient status, including zinc, provided that a suitable food vehicle which is centrally processed is available. Alternatively, fortification could be targeted for certain high risk groups (e.g. complementary foods for infants). Efforts should be made to develop protected fortificants for zinc, so that potent inhibitors of zinc absorption (e.g. phytate) present either in the food vehicle and/or indigenous meals do not compromise zinc absorption. Fortification does not require any changes in the existing food beliefs and practices for the consumer and, unlike supplementation, does not impose a burden on the health sector. A quality assurance programme is required, however, to ensure the quality of the fortified food product from production to consumption. In the future, dietary modification/diversification, although long term, may be the preferred strategy because it is more sustainable, economically feasible, culturally acceptable, and equitable, and can be used to alleviate several micronutrient deficiencies simultaneously, without danger of inducing antagonistic micronutrient interactions. Appropriate dietary strategies include consumption of zinc-dense foods and those known to enhance zinc absorption, reducing the phytic acid content of plant based staples via enzymic hydrolysis induced by germination/fermentation or nonenzymic hydrolysis by soaking or thermal processing. All the strategies outlined above should be integrated with ongoing national food, nutrition and health education programmes, to enhance their effectiveness and sustainability, and implemented using nutrition education and social marketing techniques. Ultimately the success of any approach for combating zinc deficiency depends on strong advocacy, top level commitment, a stable infrastructure, long term financial support and the capacity to control
\end{abstract}


quality and monitor and enforce compliance at the national or regional level. To be cost effective, costs for these strategies must be shared by industry, government, donors and consumers.

\section{Introduction}

Micronutrient deficiencies are a widespread public health concern. Dietary inadequacies of iodine, vitamin $\mathrm{A}$, and iron are presently estimated to adversely affect the health, mental and physical function, and survival of more than 2 billion people in the world, even though such inadequacies have been documented for more than a decade. In contrast, the severe negative effects of zinc deficiency on human health in developing countries have only recently been recognized by the United Nations. Zinc was omitted from the United Nations (1991) micronutrient priority list, in part because of a lack of awareness of the importance of zinc in human nutrition; the nonspecific clinical features of zinc deficiency (i.e. impaired growth and immune function, poor appetite and taste acuity); lack of a recognized sensitive and specific index of zinc status; and finally a lack of data on the zinc and antinutrient content of local staple foods in developing countries. In retrospect the omission of zinc from the United Nations micronutrient priority list was very unfortunate because zinc deficiency in developing countries is likely to be as prevalent as nutritional iron deficiency.

The first cases of human zinc deficiency, described in the 1960s, were male adolescents from the Middle East consuming plant based diets containing high levels of antinutrients, known to inhibit zinc absorption: intakes of flesh foods were low (Prasad et al. 1963). This dietary pattern is common not only in the Middle East but in many other developing countries. During childhood, zinc deficiency causes stunting and impaired cognitive function and increases the incidence and severity of acute and persistent diarrhoea, acute lower respiratory infections, and possibly the incidence of malaria caused by Plasmodium falciparum (Hambidge, 1997). In pregnancy, zinc deficiency may contribute to complications and low birth weight (Tamura \& Goldenberg, 1996). Additionally, some non-nutritional factors may exacerbate any deficiency of zinc, and at the same time compromise iron status. These include chronic intestinal blood loss through parasite infections such as hookworm (Stoltzfus et al. 1997), chronic haemolysis induced by malaria and schistosomiasis (Williams \& Naraqi, 1979), and for women of child-bearing age, menstruation and frequent reproduction cycling (Halberg, 1992). Interactions with other micronutrients may result in zinc deficiency exacerbating other micronutrient deficiency states (e.g. vitamin A ) (Udomkesmalee et al. 1990).

With the recognition of the impact of zinc deficiency on human health comes the need to develop programmes to combat this deficiency, preferably by incorporating zinc into preexisting micronutrient intervention strategies. This review examines possible intervention strategies to combat zinc deficiency in developing countries.

Three nutrition intervention strategies have been used with varying success to combat deficiencies of vitamin A, iron and iodine: supplementation, fortification and dietary diversification/modification. These same strategies can also be designed to simultaneously alleviate zinc deficiency with only a modest addition to the overall costs of the programme. Implementation of these strategies in developing countries requires the combined resources of government, industry, public health educators, donors, scientists, nongovernmental organizations and consumers. 


\section{Supplementation}

In developing countries, supplementation programmes are expensive short term strategies that rely heavily on donor support and individual compliance. They are only appropriate for populations where the micronutrient status, such as the zinc status, must be improved over a relatively short time period. Supplementation is appropriate when the requirements cannot be met from habitual dietary sources (e.g. pregnant women, low birthweight infants, infants and children with acute or persistent diarrhoea and those recovering from severe malnutrition). Furthermore, a health system capable of providing a consistent supply, distribution, delivery and consumption of the zinc supplement to the targeted group(s) is also required. All too often supplementation programmes have failed because of poor compliance, poor coverage, absence of commitment at the national and community levels and poorly designed communication messages. Increased burden to already overloaded health care delivery systems may also be a contributing factor (Gillespie et al. 1991).

More qualitative research is required to understand the complex reasons for poor compliance in supplementation programmes. In iron supplementation programmes, poor compliance has often been linked with the onset of side effects. However, behavioural barriers are also implicated, especially during pregnancy when long term medication is thought to be harmful to the baby or result in a bigger baby and therefore delivery difficulties (Galloway \& McGuire, 1994).

Zinc supplements can be given alone or as a component of multimicronutrient supplements such as prenatal iron and folate. Care must be taken when formulating these multimicronutrient supplements to use salts that are readily absorbed, and levels that will not induce antagonistic interactions among major and trace elements. For zinc, possible interactions between zinc and calcium (Wood \& Zheng, 1997), zinc and non-haem iron (Solomons, 1986) and zinc and copper (Yadrick et al. 1989; Fischer et al. 1984) should be considered.

When given alone, zinc supplements should be administered in the fasting or postabsorptive state to avoid any dietary components interfering with zinc absorption (Oelshlegel \& Brewer, 1977). In contrast, multimicronutrient supplements should be consumed with food because the presence of the ligands in food appears to minimize the inhibitory effect of nonhaem iron on zinc absorption (Valberg et al. 1984; Sandström et al. 1985; Walsh et al. 1994) and vice versa (Crofton et al. 1989; Yadrick et al. 1989; Brown et al. 1997).

There are currently three major barriers to effective zinc supplementation programmes. The first is the high frequency of the dose required. Most of the zinc in the human body exists in nonlabile pools (e.g. muscle and bone) and is not normally released during zinc deprivation (Aggett \& Comerford, 1995). Furthermore, daily rather than intermittent doses of zinc were required to produce a body growth response that fully compensated for a previously deficient zinc intake in rats (Momciloviç, 1995). Hence, unlike iron supplements, weekly or twice weekly doses may not be as effective as smaller doses given daily. Bates et al. (1993) gave $70 \mathrm{mg}$ zinc as zinc sulphate twice weekly for 1.25 years in a double-blind zinc supplementation study of Gambian infants but did not observe any significant effect of the zinc supplement on biochemical indices of zinc status. Small changes in arm circumference, an improvement in urinary lactulose : creatinine molar ratio (an index of intestinal permeability) and a trend towards fewer malaria episodes were observed.

Secondly, uncertainty still exists about the best type of zinc salt to use in relation to bioavailability and side effects. Both salt-solubility-dissolution and intragastric $\mathrm{pH}$ are known to influence oral zinc absorption (Sturniolo et al. 1991). Human studies of zinc absorption from zinc ascorbate, methionine, histidine, citrate, gluconate, picolinate, oxide and aminoate, mea- 
sured by the oral zinc tolerance method, have given varying and sometimes conflicting results (Barrie et al. 1987; Schölmerich et al. 1987; Prasad et al. 1993; Rosado et al. 1993; Henderson et al. 1995). Prasad \& co-workers (1993) recommended oral zinc acetate because it is well tolerated and readily available, especially at low intragastric $\mathrm{pH}$, and is comparable and/or superior to zinc sulphate and zinc aminoate; others advocate using zinc methionine and zinc histidine despite their association with increased urinary zinc excretion (Schölmerich et al. 1987; Rosado et al. 1993). Zinc oxide is poorly absorbed, the low solubility at the basic pH of the small intestine preventing it from dissociating in the gastrointestinal tract (Prasad et al. 1993; Wolfe et al. 1994; Henderson et al. 1995). In a study of pregnant adolescents receiving prenatal supplements of iron and elemental zinc as oxide or sulphate, plasma zinc levels of those receiving the supplemental zinc oxide $(25 \mathrm{mg} \mathrm{Zn})$ remained at levels comparable to those of the unsupplemented women; only those receiving the zinc sulphate $(20 \mathrm{mg} \mathrm{Zn})$ supplement had increased plasma zinc concentrations (Wolfe et al. 1994). To date, most zinc supplementation studies in humans have used either the sulphate, acetate, gluconate, or amino acid chelates of zinc (Gibson et al. 1989; Cavan et al. 1993; Gibson, 1994; Sazawal et al. 1995; Rosado et al. 1997). More research is necessary on the mechanisms underlying the absorption and utilization of zinc to identify the most effective dietary zinc supplement.

The current recommended preventive doses of supplemental zinc for infants and children are $5 \mathrm{mg} / \mathrm{d}$ for children less than 5 years, and $10 \mathrm{mg} / \mathrm{d}$ for those over 5 years (Gibson et al. 1989; Tomkins et al. 1993), although in some developing countries where the zinc status is likely to be very poor, even higher doses may be necessary (Gibson, 1994; Sazawal et al. 1995). During pregnancy, preventive doses of $20-25 \mathrm{mg}$ elemental zinc per day, generally as zinc sulphate, have been most frequently used (Swanson \& King, 1987; Tamura \& Goldenberg, 1996). At this level of zinc supplementation (i.e. $25 \mathrm{mg} \mathrm{Zn}$ as zinc sulphate), significant improvements in birth weight and head circumference were reported in the infants of otherwise healthy African American zinc-supplemented women with below average initial plasma zinc levels compared with their counterparts receiving a placebo (Goldenberg et al. 1995). Routine zinc supplementation may be advisable in early adolescence in countries where zinc deficiency is likely to be endemic, to ensure that women enter pregnancy with optimal zinc nutriture.

For children with protein-energy malnutrition and persistent diarrhoea, a daily treatment dose of $\sim 4 \mathrm{mg} / \mathrm{kg}$ body weight of elemental zinc is recommended, preferably given in two daily doses as a syrup. For a male child 6-8 years old this corresponds to $80 \mathrm{mg} / \mathrm{d}$. Such zinc supplements dramatically reduce stool volume and diarrhoea duration (Sachdev et al. 1990), and improve intestinal permeability and thus appetite (Roy et al. 1992). Chronic overdosage of zinc (i.e. 100-300 mg Zn/d for adults) may induce copper deficiency (Prasad et al. 1978) and alterations in the immune response and serum lipoprotein levels (Chandra, 1984). Some of these disturbances may also occur at lower doses (i.e. $50 \mathrm{mg} \mathrm{Zn} / \mathrm{d}$ ) although the data are conflicting and require confirmation (Hooper et al. 1980; Freeland-Graves et al. 1982; Black et al. 1988; Yadrick et al. 1989). Doses of $25-35 \mathrm{mg} \mathrm{Zn/d} \mathrm{do} \mathrm{not} \mathrm{appear} \mathrm{to} \mathrm{pose} \mathrm{a} \mathrm{health} \mathrm{hazard}$ (Smith, 1994). Overt toxicity symptoms such as nausea, vomiting, epigastric pain, lethargy and fatigue may occur with extremely high zinc intakes (Fosmire, 1990).

\section{Fortification}

Fortification with multiple micronutrients including zinc could be a cost effective sustainable method for improving zinc status at a national level in countries where zinc deficiency is endemic. Alternatively, fortification can be targeted in specific regions and/or for certain high 
risk groups (e.g. weaning foods for infants) within a country. Fortification does not require any changes in the existing food beliefs and practices of the consumer and, unlike supplementation, does not impose a burden on the health sector. Moreover, because the cost of fortification is borne by industry and the consumer, the costs to governments are generally low. Multiple micronutrient fortification is more cost effective than single fortification and, like supplementation, requires both an efficient production and distribution system within the country to be successful.

A critical factor determining the selection of the food product to be fortified is whether it is consumed either widely or preferentially by the at-risk groups. For fortification programmes to be effective, at least $50 \%$ of the population at risk of zinc deficiency should consume the potential food vehicle throughout the year. Also, intakes of the food product at a relatively low level of consumption must be sufficient to provide adequate zinc to the population most at risk of deficiency, whereas at higher consumption levels there should be no risk of toxicity. A guide on the collection of food consumption levels for potential food vehicles is available (FitzGerald, 1997). Information on methods of storage, food processing and preparation of the potential food vehicle must also be available to assess any potential losses of the fortificant (FitzGerald, 1997).

Fortification also requires a food vehicle which is centrally processed, temperature stable, technologically and economically fortifiable, and undergoes no changes in taste, texture and appearance during storage. Prior to commercial production, the absorption of zinc from different indigenous meals containing the fortified food vehicle must be quantified. If the potential food vehicle and/or the indigenous meals contain potent inhibitors of zinc absorption (e.g. phytate), the added zinc (and iron), like the intrinsic zinc and iron, will be poorly absorbed, and hence have limited effect on the zinc and iron status of the consumer. In such cases, efforts should be made to develop protected fortificants for zinc (i.e. fortificants that prevent zinc from binding to phytic acid), similar to those developed for iron.

Successful fortification also depends on the availability of an appropriate fortificant. It must be readily absorbed and utilized, resistant to any dietary inhibitors of zinc absorption, safe, stable, acceptable, and have no effect on the organoleptic qualities of the food vehicle. Currently, in industrialized countries, zinc oxide is most frequently used for fortifying cereals because it is a cheap white powder that causes no organoleptic problems. However, because it is insoluble at high intragastric $\mathrm{pH}$, it has only low to moderate bioavailability (Henderson $e t$ al. 1995). In experimental rat studies based on zinc in the tibia, zinc from zinc oxide was said to have $61 \%$ availability relative to zinc sulphate (Wedekind \& Baker, 1990). It is possible that its solubility could be improved by the concomitant addition of certain organic chelators (e.g. cysteine) (Desrosiers \& Clydesdale, 1989). Heptahydrate zinc sulphate has also been used in the past in the US for fortifying blended foods (Combs et al. 1994). Although it is better absorbed than zinc oxide, it is six times more expensive and is not resistant to dietary inhibitors.

Sodium iron EDTA is an example of a bioavailable protected iron compound strongly recommended for use in developing countries because it does prevent iron from binding with the phytic acid in cereals (INACG, 1993), and may even enhance absorption of other intrinsic inorganic iron (Viteri et al. 1995). However, although it is better absorbed, it is six times more expensive than ferrous sulphate. Sodium iron EDTA also apparently increases the absorption of zinc from meals containing phytic acid (Davidsson et al. 1994) and such EDTA-containing compounds may be the fortificant of choice for developing countries.

Concern about whether intakes of EDTA could exceed the FAO/WHO (1993) acceptable daily intake level $(2.5 \mathrm{mg} / \mathrm{kg})$ led Beaton (1995) to estimate intakes of EDTA for various age 
groups based on data on food consumption from Kenya. Calculated mean intakes for even the highest intake group (school children) were well below the FAO/WHO (1993) acceptable daily intake. Research must be pursued however on the possible influence and physiological effect of EDTA-containing compounds on absorption of potentially toxic metals $(\mathrm{Pb}, \mathrm{Hg}, \mathrm{Al}, \mathrm{Mn}$ ) (Hurrell, 1997).

The amounts of micronutrients currently added to cereals in most industrialized countries are generally based on restoration levels (i.e. adding enough to refined flour to restore the level to that of the unrefined cereal). In developing countries zinc should be added at levels that are higher than that normally present in the natural food substances (i.e. true fortification). Some of the factors that must be taken into account when selecting the fortificant level have already been discussed in relation to choice of the potential food vehicle. They include per capita consumption of the food vehicle; food preparation and processing methods of the food vehicle; dietary components that inhibit or enhance the bioavailability of the fortificant; possible antagonistic interactions with other multimicronutrient fortificants; prevalence of zinc deficiency within the target population; and estimated requirements for zinc (Lotfi et al. 1996). Details on how to calculate the optimal fortificant levels for a food product are given in FitzGerald (1997). If the fortified food vehicle is consumed by both adults and children, careful attention must be given to prevent excessive intakes of zinc by young children whose requirements are less. Obviously, the fortification level must take into account the toxic threshold level for zinc for normal individuals. The US daily reference dose (RfD) is set at $0.3 \mathrm{mg} / \mathrm{kg}$, based on a lowest-observed-adverse-effect level (LOAEL) of $1.0 \mathrm{mg} / \mathrm{kg}$. The RfD represents an estimate of a daily exposure (including sensitive subgroups) that is likely to be without appreciable risk of deleterious effects during a lifetime (US EPA, 1992). Discussion of the appropriateness of the US RfD is given in Smith (1994).

The cost of fortifying food staples is relatively low compared with their total cost. Beaton (1995) estimated the additional cost of fortifying milled cereals with a multimicronutrient premix for refugee feeding to be about US\$37/MT, of which only about US\$10/MT is for the cost of the micronutrient additions. Combs et al (1994) estimated the cost of a micronutrient premix for US corn-soy blended food to be approximately US\$5/MT; cost for zinc alone (as zinc sulphate monohydrate) at the level of $240 \mathrm{~g} / \mathrm{MT}$ was US $\$ 1 \cdot 10 / \mathrm{MT}$.

To date, multiple micronutrient fortificants that include zinc have been used with only a limited number of food vehicles. Foods in the US that are frequently enriched or fortified with zinc and iron include flour, bakery goods, breakfast cereals, cereals, macaroni and infant formulas and infant foods. Stable isotope studies indicate that the level of iron currently used to fortify foods in the US has no adverse effect on zinc absorption (Combs et al. 1994).

In 1995 Action Internationale Contra la Faim (AICF) formulated a micronutrient premix powder to be added to cereal/pulse based diets for supplementary feeding programmes. Fortificant levels were calculated to sustain health or growth or recovery from mild/moderate malnutrition and are not adequate for treating frank deficiencies. The zinc salt recommended was heptahydrate zinc sulphate. The recommended levels were expressed in nutrient density terms using the EU Population Reference Intake (CEC, 1994) and the UK Reference Nutrient Intake (COMA, 1991) and adjusted to take into account the health, dietary and environmental status of refugees. Details of the composition and derivation of the levels for the premix are given in Golden et al. (1995). Table 1 compares the levels (per $100 \mathrm{kcal}$ ) in cereal/pulse based diets, fortified with the AICF micronutrient premix, with the micronutrient densities recommended by Beaton (1995) for a cereal fortification premix. The latter premix, unlike that of the AICF, was designed for addition to the cereal based diet of the general population of refugees in Africa, and not targeted specifically for those with mild/moderate malnutrition. Two 
Table 1. Proposed levels for micronutrient fortificants (per $100 \mathrm{kcal}$ food) based on cereal/legume mixtures for refugee feeding

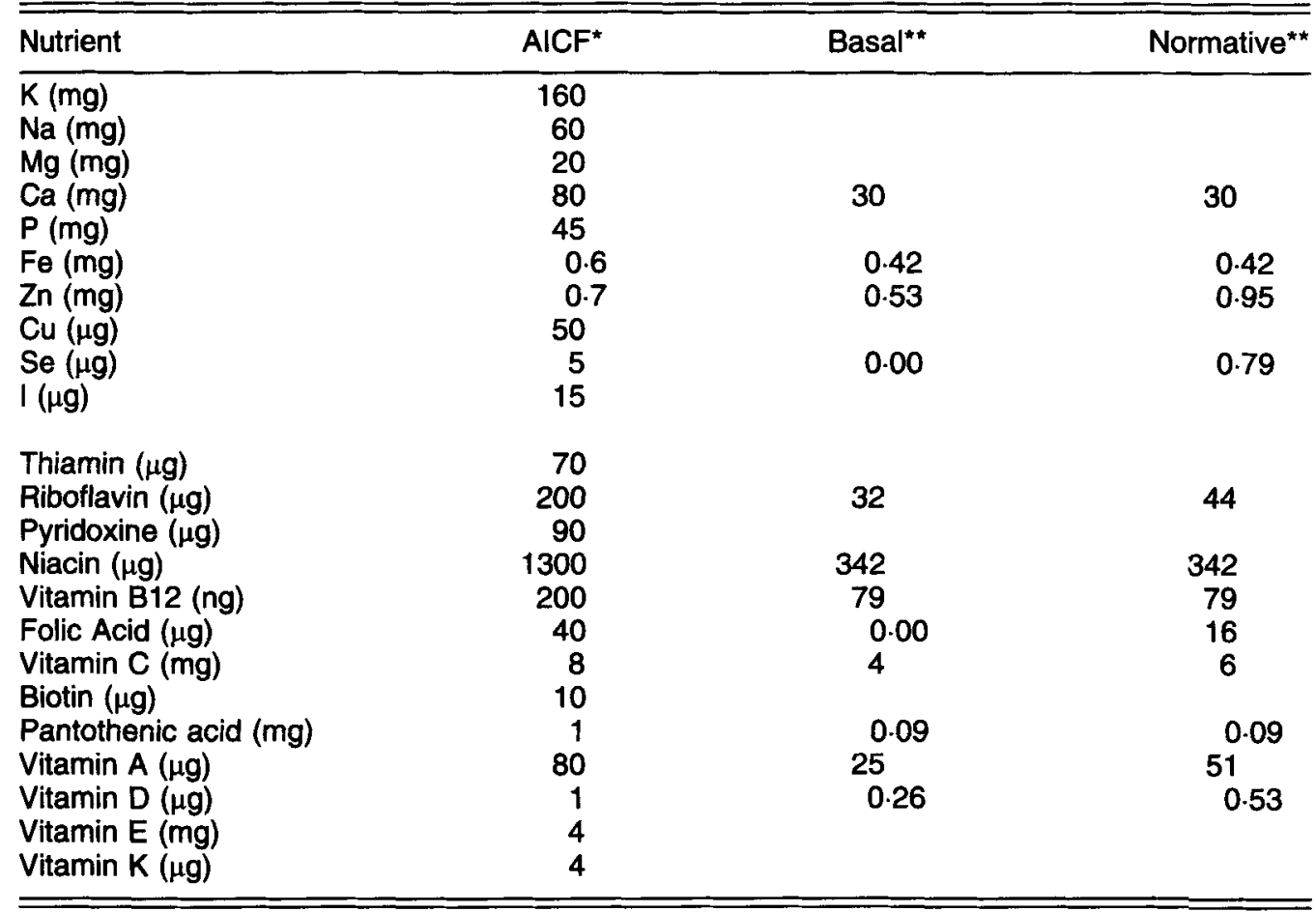

* levels for mild/moderately malnourished refugees; "* levels for general population of refugees AICF, Action Internationale Contra la Faim

micronutrient fortificant levels are given: one based on the FAO/WHO basal requirement and the other on the corresponding normative requirement estimates (FAO/WHO, 1988; WHO, 1996). Note that the zinc level using the AICF micronutrient fortificant, expressed per $100 \mathrm{kcal}$, is between the two levels based on the basal and normative requirement estimates formulated by Beaton (1995). The levels of calcium, iron and copper for the two were selected to minimize risk of antagonistic interactions (Wood \& Zheng, 1997; Solomons, 1986; Yadrick et al. 1989; Cook et al. 1991).

The World Health Organization (WHO) has also produced a micronutrient premix powder for treating infants and children in refugee camps with severe malnutrition and persistent diarrhoea (ISGPD, 1996). The zinc salt used in this premix is zinc gluconate. The safety and effectiveness of this premix for treating severe malnutrition in refugee camps in Africa has recently been established.

There is also an urgent need in developing countries to fortify complementary foods with multimicronutrients. Table 2 presents selected major and trace mineral densities of three complementary foods used in sub-Saharan Africa (Gibson et al. 1997). The mineral densities are compared with the corresponding desired nutrient densities for complementary foods calculated by Brown et al. (1997). The estimates are for an infant 9-11 months old, assuming an average volume and composition of breast milk and three 250 gram meals/d. Note that the nutrient densities for calcium, zinc, and iron in the three complementary foods are well below the desirable levels. The high phytate : zinc molar ratios of the diets exacerbate the situation as 
Table 2. Nutrient density (per $100 \mathrm{kcal}$ ) of three weanling porridges compared with nutrient density desired for child of $9-11$ months

\begin{tabular}{lcccc}
\hline \hline & $\begin{array}{c}\text { Unrefined } \\
\text { maize 80\%, } \\
\text { soya 20\% }\end{array}$ & $\begin{array}{c}\text { Unrefined maize } \\
70 \%, \text { groundnuts } \\
20 \% \text {, sorghum 10\% }\end{array}$ & $\begin{array}{c}\text { potato 70\%, } \\
\text { green leaves 19\%, } \\
\text { cowpeas 9\%, oil 2\% }\end{array}$ & Desired levels \\
\hline Calcium (mg) & 13 & 6 & 3 & 78 \\
Zinc $(\mathrm{mg})$ & 0.67 & 0.61 & 0.27 & $0.7(\mathrm{H}), 2.4(\mathrm{~L})$ \\
Copper $(\mathrm{mg})$ & 0.20 & 0.08 & 0.11 & 0.2 \\
Iron $(\mathrm{mg})$ & 0.89 & 0.7 & 1.0 & $1.5(\mathrm{H}), 4.6(\mathrm{~L})$ \\
[Phy]/[Zn] & 30 & 23 & 21 & $<15$ \\
\hline \hline
\end{tabular}

$H$, high bioavailability; L, low bioavailability; Phy, phytate

the availability of the minerals is likely to be low. Nutrient densities for niacin, riboflavin and vitamin A may also be inadequate depending on the composition of the complementary foods and the amount and composition of breast milk consumed (NAS, 1991).

In some developing countries where zinc deficiency is widespread, no centrally processed food vehicle exists. In these circumstances, fortification at the village or household level using vitamin/mineral premix powders may be an alternative strategy. Bressani et al (1972) investigated the feasibility of community based fortification of lime soaked maize in Guatemala and devised some innovative strategies for enforcing quality control at the village level. For example, the miller was supplied with a series of labelled cups such that if a householder came with maize weighing $8 \mathrm{~kg}$, cup \#8 would be used to measure out the amount of premix to be added to an $8 \mathrm{~kg}$ batch of maize.

Techniques have also been developed for use in developing countries for the fortification of unmilled whole cereal grains. These include coating, infusion or the use of extruded grain analogues. Addition of the fortified grains to normal unfortified grains generally occurs at the rate of $1: 200$. To date both the difficulty of completely masking the fortified whole grains in the final mixture and their cost have limited the application of these techniques (Lotfi et al. 1996).

Finally, a quality assurance programme is essential to ensure the quality of fortified food products from production to consumption. Both internal monitoring within the production plant and external monitoring by independent agencies is required; details of these strategies are summarized in Lotfi et al. (1996). Governments can facilitate successful quality assurance programmes by developing standards and associated legislation and enforcing the regulations. Quality control for fortification programmes at the village or household level is likely to prove difficult.

To be successful at a national level, fortification must be mandated by government regulations that eliminate competition with unfortified products, ensure quality and safety of the zinc-fortified foods and honest and fair practices in marketing them. As well, governments can assist national fortification policies by exempting imported food technology and fortificant mixes from tariffs.

The efficacy of all fortification programmes should be tested under the conditions of normal distribution and in the appropriate dietary setting before they are released on the market. After their implementation, steps should be taken to monitor and evaluate both the effect of and compliance with the programme. Ultimately, to be successful, fortification must be a profitable business proposition, although costs may be shared by industry, government, donors and consumers (Gillespie et al. 1991). 


\section{Dietary modification/diversification}

Both supplementation and fortification rely on a stable infrastructure and require financial support on a long standing sound economic basis. However, the third strategy, dietary modification/diversification, is a more sustainable, long term, economically feasible, equitable, and culturally acceptable strategy which can be used to alleviate several micronutrient deficiencies simultaneously without risk of antagonistic interactions. It involves changes in food selection patterns and/or traditional household methods for preparing and processing indigenous foods, with the overall goal of enhancing the availability, access, and utilization of foods with a high content and bioavailability of zinc throughout the year. To implement effective dietary strategies, knowledge of the local dietary patterns, food beliefs, preferences and taboos is required, as well as the ability to change attitudes and practices.

In those developing countries where diets are predominantly cereal based and fermented cereals are not widely consumed, the major causative factor of zinc deficiency is not low zinc intakes, but poor zinc absorption. In contrast, for countries with diets based on starchy roots and tubers, low zinc intakes are a major determinant of zinc deficiency because these staples are poor sources of dietary zinc (Gibson, 1994). A variety of methods are therefore appropriate to combat zinc deficiency. The more important of these methods are outlined briefly below. Each aims to increase the total zinc intake and/or the absorption of dietary zinc.

\section{Improved cereal varieties}

Intakes of zinc can be increased by persuading farmers to grow new cereal varieties. Some of these have higher zinc concentrations than earlier strains and tolerate zinc deficient soils. These 'zinc-efficient genotypes' are also more disease resistant, have improved seedling vigour, enhanced germination and a higher grain yield (Graham et al. 1992). Hence their use will not decrease crop productivity or increase costs to farmers. For some cereals (e.g. maize), the genetic potential exists to increase the level of methionine in the mature maize kernel. This is important because enhanced zinc absorption has been reported in rats fed mature maize kernels with dietary supplements of methionine or cysteine (House et al. 1996). Reducing the phytic acid concentration of certain cereals by plant breeding is also now a feasible strategy for enhancing zinc absorption (Raboy, pers. comm.).

\section{Addition of enhancers of zinc absorption}

Zinc absorption can be enhanced by the increased consumption of foods such as cellular animal proteins (meat, poultry and fish). Certain sulphur amino acids (methionine and cysteine) and cysteine-containing peptides, released during the digestion of cellular animal proteins, and organic acids (e.g. citric and lactic acid) produced during fermentation enhance zinc absorption, and can counteract the negative effect of phytic acid, even when levels of zinc in the diet are only modestly increased (Sandström et al. 1989). The mechanism is unclear: naturally occurring mineral chelates may exist in animal protein (Scott \& Zeigler, 1963). Alternatively, soluble ligands with zinc may be formed which facilitate zinc absorption (Snedeker \& Greger, 1983) or prevent the formation of the insoluble zinc-phytate complex (Sandström et al. 1980). 
The phytic acid content of cereals which have the acid localized in the outer aleurone layer (e.g. wheat, rice, sorghum) or in the germ (e.g. maize) can be reduced by modifying milling practices (O'Dell et al. 1972). Careful milling can also reduce the dietary fibre content, which may enhance zinc absorption to some degree. For legumes such as peas and beans, the cotyledons and not the seed coat contain most of the phytate so that when the coat is removed, the phytate content actually increases.

\section{Soaking to reduce phytic acid content}

Most plant based foods contain some phytase enzymes (myo-inositol hexaphosphate phosphohydrolases) (EC 3.1.3.26), although in dry or dormant seeds activity is negligible. Phytase enzymes hydrolyse phytic acid (myo-inositol hexaphosphate; IP6) to lower inositol phosphates (IP4-IP1) which do not form insoluble complexes with zinc (Lönnerdal et al. 1989). Hence, knowledge of the optimal conditions for enhancing phytase activity in plant based diets is important.

The level of endogenous phytase activity in cereals depends on the species and variety. It is high in rye and wheat but very low in maize and sorghum, the two cereal staples of sub-Saharan Africa (Table 2) (Gibson et al. 1997). Soaking can activate endogenous cereal phytases, although conditions must be controlled as the activity depends on the $\mathrm{pH}$ of the medium and temperature; $\mathrm{pH}$ 5.0-4.5 appears to be optimal for cereal phytases (Cheryan, 1980). Soaking at room temperature initiates optimal endogenous phytase activity in maize (Zea mays), white sorghum (Sorghum bicolor), and soyabeans, whereas for wheat (Triticum aestivum) and several varieties of beans such as mung beans (Phaseolus aureus) and lima beans ( $P$. lunatus), temperatures of about $60^{\circ} \mathrm{C}$ are optimal.

Soaking has also been advocated as a practical, nonenzymic, household method to reduce the phytic acid content of certain cereals (e.g. maize), and most legumes, including soyabeans. Some of the phytic acid in these staples is stored in a relatively water-soluble form such as sodium or potassium phytate, and hence can be removed by diffusion. The reported proportion of water-soluble phytate ranges from $10 \%$ in defatted sesame meal to 70-97\% in red kidney beans, corn germ and soy flakes (De Boland et al. 1975; Chang et al. 1977). Discrepancies in the reported levels of soluble phytate in these staples can be attributed to variations in the conditions used to extract the phytic acid, particularly the $\mathrm{pH}$, and the confounding effects of protein, calcium and magnesium ions (Tabekhia \& Luh, 1980). Soaking may also remove other antinutrients such as saponins and polyphenols.

\section{Germination to increase phytase activity}

Germination increases phytase activity in seeds through induction and/or de novo synthesis; phytase levels may increase by 23-588\% after 2-3 days depending on the cereal (Table 3).

Phytase-induced reductions in inositol hexaphosphate content after $2-3 \mathrm{~d}$ germination of cereals can range from $52 \%$ for rice to $21-28 \%$ for white corn (Table 4 ). The concentration of minerals (including zinc) and other nutrients (e.g. protein, nucleic acids, certain amino acids, water-soluble B vitamins) do not change during germination; any reported increases may arise from losses as a result of transpiration during sprouting (Lorenz, 1980). Nevertheless, germi- 
Table 3. Change in phytase activity during germination

\begin{tabular}{lcccc}
\hline \hline Cereal & $\begin{array}{c}\text { No. of } \\
\text { treatment days }\end{array}$ & $\begin{array}{c}\text { Before } \\
\text { germination }\end{array}$ & $\begin{array}{c}\text { After } \\
\text { germination }\end{array}$ & $\begin{array}{c}\text { \% Increase in } \\
\text { phytase activity }\end{array}$ \\
\hline Corn, yellow, US & 3 & 46 & 76 & 65 \\
Corn, white, US & 3 & 38 & 196 & 416 \\
Corn, white, & 3 & 24 & 165 & 588 \\
$\quad$ Malawi & & & & \\
Sorghum & 3 & 67 & 203 & 203 \\
Soyabeans & 2 & 114 & 188 & 65 \\
Wheat & 2 & 2002 & 3090 & 54 \\
Rye & 2 & 4931 & 6081 & 23 \\
\hline \hline
\end{tabular}

Table 4. Myo-inositol hexaphosphate content $(\mathrm{mg} / 100 \mathrm{~g}$ dry weight) of selected cereals before and after germination

\begin{tabular}{lrcccc}
\hline \hline Cereal & Start & 1 day & 2 days & 3 days & $\%$ change \\
\hline Corn, yellow & 870 & 880 & 780 & 760 & 13 \\
Corn, white, Malawi & 1460 & - & 1180 & 1050 & 28 \\
Corn, white, US & 1160 & - & 990 & 920 & 21 \\
Millet & 1140 & 870 & 760 & - & 33 \\
Rice & 1260 & 960 & 1030 & 590 & 53 \\
Rye & 1180 & 1050 & 960 & - & 19 \\
Sorghum & 1450 & 1510 & 1460 & 1400 & 4 \\
Soyabeans & 1330 & 1070 & 1020 & - & 23 \\
Wheat & 1650 & 1410 & 980 & - & 41 \\
\hline \hline
\end{tabular}

nation decreases the tannin content of some beans (e.g. Vicia faba) and red sorghum, owing to the formation of complexes with proteins and the gradual degradation of oligosaccharides (Lorenz, 1980).

To enhance phytase-induced phytate hydrolysis, some germinated cereal flour can be added to ungerminated cereal flours. For example, the addition of $10 \%$ germinated maize flour to maize dough was reported to decrease the phytic acid content of kenkey in Ghana by $56 \%$ (Amoa \& Muller, 1975); even greater phytate reductions can be achieved if these doughs or flour slurries are incubated at the optimal temperature, $\mathrm{pH}$, and time, to maximize phytase activity.

During the germination of cereals, but not legumes, the activity of $\alpha$-amylase (EC 3.2.1.1) increases, resulting in the hydrolysis of amylose and amylopectin to dextrins and maltose (Lorenz, 1980). As a result, the addition of germinated cereal flours (at levels of 5-10\%) reduces the viscosity of thick cereal porridges prepared from flour concentrations of between 20 and $25 \%$. Such porridges have an initial viscosity of possibly $50000 \mathrm{cP}$ and this is reduced to an easy-to-swallow semi-liquid consistency (i.e. $3000 \mathrm{cP}$ ) suitable for infant feeding without further dilution with water (Mosha \& Svanberg, 1990) (Table 5). Consequently, gruels with a higher energy density $(4.2 \mathrm{~kJ} / \mathrm{g} v .0 .84 \mathrm{~kJ} / \mathrm{g})$ and zinc content, but lower [Phy]/[Zn] molar ratios, can be prepared and used for infant feeding. Care must be taken to ensure that all porridges and doughs prepared from germinated flours are decontaminated by heating prior to 
Table 5. Changes in viscosity of rice porridge ( $25 \%$ dry matter) after the addition of germinated sorghum

\begin{tabular}{lc}
\hline \hline Amount of germinated sorghum added $(\%)$ & Viscosity (cP) \\
\hline 0 & 37200 \\
2 & 12400 \\
4 & 6800 \\
5 & 6400 \\
6 & 6400 \\
\hline \hline
\end{tabular}

Modified from Gopaldas et al. (1986).

use, because germination increases the concentration of Enterobacteriaceae, fungi, Bacillus spp. etc. including potential pathogenic and toxigenic species (Nout, 1993).

\section{Fermentation to increase microbial phytase activity}

Fermentation induces phytate hydrolysis via the action of microbial phytases (EC.3.1.3.8) which can originate either from the microflora on the surface of the seeds, or by inoculation with microbial starter cultures (Chavan \& Kadam, 1989). The microbial activity results in organic acid production, hence lowering the $\mathrm{pH}$ of the cereal dough or flour slurry below the optimal range for cereal phytases (i.e. $\mathrm{pH}$ 5.0-4.5). The exogenous microbial phytases then assume a greater role as their activities remain optimal over a lower and broader $\mathrm{pH}$ range (i.e. 2.5-5.5) than cereal phytases (4.5-5.5). Fermentation should be carried out for at least 16-24 hours at $25-30^{\circ} \mathrm{C}$ to ensure that the $\mathrm{pH}$ of the cooked dough or porridge falls to a level that reduces the growth of diarrhoeal pathogens (i.e. < pH 3.8) (Mensah et al. 1991).

Use of an enrichment inoculum is preferred because the time required to achieve phytate hydrolysis is reduced; reductions of up to $95 \%$ in the IP-5 and IP-6 content have been reported after fermentation at $25-30^{\circ} \mathrm{C}$ for $16-24 \mathrm{~h}$. Use of high tannin cereals should be avoided because the tannins inhibit phytase activity and also further inhibit the bioavailability of iron (Svanberg et al. 1993). Starter cultures derived from natural, lactic-acid-fermented millet or maize gruel prepared by the traditional 'back-slopping' method using anaerobic fermentation at $30^{\circ} \mathrm{C}$ can be used to inoculate the flour slurries or doughs. Alternatively, commercial phytase enzymes prepared from moulds (e.g. Aspergillus oryzae or A. niger) that are stable over an even wider $\mathrm{pH}$ (3.5-7.8) and temperature range can also be used (Turk \& Sandberg, 1992; Sandberg et al, 1996), although their high cost precludes their use in many developing countries at the present time.

Fermentation has several other advantages: it reduces the energy required for cooking and improves the safety of the final food product because the reduced $\mathrm{pH}$ inhibits growth of diarrhoeal pathogens; antimicrobial substances may also be produced during fermentation.

To date, in vivo comparisons of the bioavailability of zinc (and iron) in fermented and unfermented cereal based foods such as porridges prepared for infant and child feeding are not available. Increases in in vitro measurements of soluble iron have been reported in porridges fermented with togwa as an enrichment inoculum, with and without the addition of commercially prepared phytase enzyme (Svanberg \& Sandberg, 1988; Svanberg et al. 1993). 


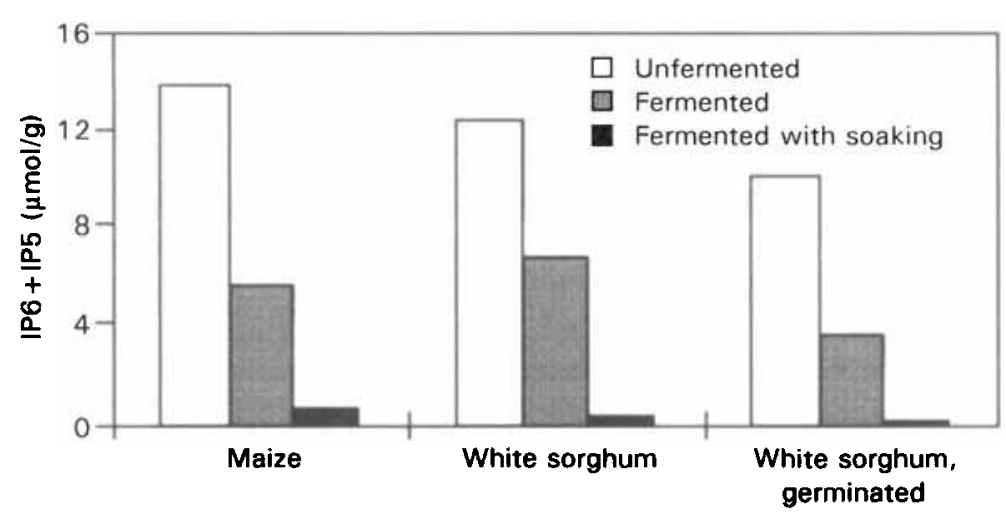

Figure 1. The IP5 + IP6 content of porridges made from unfermented, fermented and fermented and soaked cereal flours (modified from Svanberg et al. 1993). IP, inositol phosphate

\section{Combined strategies}

Flours produced from germinated and nongerminated staples can be mixed together and then soaked and fermented using a microbial starter culture. Such a combination of strategies can result in large reductions in the phytic acid content. The addition of germinated flours increases the amount of endogenous phytase activity present. Soaking prior to the addition of the starter culture allows for both diffusion of soluble phytates and a longer incubation time in the optimal $\mathrm{pH}$ range for endogenous cereal phytases before microbial activity lowers the $\mathrm{pH}$. Addition of a starter culture provides a source of microbial phytases which can hydrolyse phytic acid until the $\mathrm{pH}$ falls to $<3.8$. This takes between 16 and $24 \mathrm{~h}$, after which the fermented flours are mixed with water to form slurries and then cooked to form porridges. This combination of strategies can reduce the phytic acid content by as much as $90 \%$ (Fig. 1) while simultaneously enhancing zinc absorption, protein quality, protein digestibility, microbiological safety, and keeping quality, yet decreasing toxins such as haemagglutinins and cyanide (Svanberg et al. 1993).

Caution must be used when evaluating the effect of enzymic and nonenzymic hydrolysis of phytate in plant based staples. Inconsistencies arise because of differences in methods for the phytate and phytase assays (Xu et al. 1992). Phytase activity is generally based on the amount of released inorganic phosphate or inositol (Lolas \& Markakis, 1977). The latter could also be produced by nonspecific phosphates acting upon some lower inositol phosphates or organic sources other than phytates. Therefore, it is preferable to use the HPLC method to determine phytase activity via monitoring changes in inositol hexaphosphate levels after incubation under optimal conditions for phytase activity (Sandberg \& Andersson, 1988). The HPLC method should also be used to separate, identify, and quantify the other higher and lower myo-inositol phosphates (Lehrfeld, 1989).

\section{Conclusions}

Widespread zinc deficiency is likely to exist in developing countries where diets are predominately plant based and intakes of animal tissues are low. An integrated approach employing targeted supplementation, fortification and dietary strategies must be used to 
maximize the likelihood of eliminating zinc deficiency at a national level. The strategies must also be integrated with ongoing national food, nutrition, and health education programs to enhance their effectiveness and sustainability, and implemented using nutrition education and social marketing techniques.

Successful implementation and sustainability of these strategies will require increased awareness of the importance of zinc in human health among bilateral and nongovernment agencies, the scientific community, and the general public. The strategies must also be coordinated in developing countries at the international, national and local levels among government, education, public health and industry. An international network on zinc nutriture in developing countries might promote such coordination.

Ultimately the success of any approach for combating zinc deficiency depends on strong advocacy, top level commitment, a stable infrastructure, long term financial support, and the capacity to control quality and monitor and enforce compliance at the national or regional level. To be cost effective, costs for these strategies must be shared by industry, government, donors and consumers.

\section{References}

Aggett, P. J. \& Comerford, J. G. (1995). Zinc and human health. Nutrition Reviews 53, S16-S22.

Amoa, B. \& Muller, H.G. (1975). Studies on Kenkey with particular reference to calcium and phytic acid. Cereal Chemistry 53, 365-375.

Barrie, S. A., Wright, J. V., Pizzorno, J. E., Kutter, E. \& Barron, P. C. (1987). Comparative absorption of zinc picolinate, zinc citrate, and zinc gluconate in humans. Agents and Actions 21, 223-228.

Bates, C. J., Evans, P. H., Dardenne, M., Prentice, A., Lunn, P. G., Northrop-Clewes, C. A., Hoare, S., Cole, T. J., Horan, S. J., Longman, S. C., Stirling, D. \& Aggett, P. J. (1993). A trial of zinc supplementation in young rural Gambian children. British Journal of Nutrition 69, 243-255.

Beaton, G. H. (1995). Fortification of Foods for Refugee Feeding; Final Report. Hull, QC, Canada: Canadian International Development Agency (CIDA).

Black, M. R., Medeiros, D. M., Brunett, E. \& Welke, R. (1988). Zinc supplements and serum lipids in young adult white males. American Journal of Clinical Nutrition 47, 970-975.

Bressani, R. (1972). The importance of maize for human nutrition in Latin America and other countries. In Nutritional Improvement of Maize (INCAP publication L-4), pp. 5-29. Guatemala: INCAP.

Brown, K., Dewey, K.G. \& Allen, L.H. (1997). Complementary feeding of young children in developing countries, a review of scientific knowledge (In Press).

Cavan, K. R., Gibson, R. S., Grazioso, C. F., Isalgue, A. M., Ruz, M. \& Solomons, N. W. (1993). Growth and body composition of periurban Guatemalan children in relation to zinc status: a cross-sectional study. American Joumal of Clinical Nutrition 57, 334-343.

Chandra, R.K. (1984). Excessive intake of zinc impairs immune responses. JAMA (Journal of the American Medical Association) 252, 1443-1446.

Chang, R., Schwimmer, S. \& Burr, H. K. (1977). Phytate: removal from whole dry beans by enzymatic hydrolysis and diffusion. Journal of Food Science 42, 1098-1101.

Chavan, J. K. \& Kadam, S. S. (1989). Nutritional improvement of cereals by fermentation. Critical Reviews in Food Science and Nutrition 28, 349-400.

Cheryan, M. (1980). Phytic acid interactions in food systems. Critical Reviews in Food Science and Nutrition 13, 297-335.

Combs, G. R., Dexter, P. B., Horton, S. E. \& Buescher, R. (1994). Micronutrient Fortification and Enrichment of P.L. 480 Title II Commodities: Recommendations for Improvement. A Technical Review Paper. Opportunities for Micronutrient Interventions.

CEC (1994). Reference Nutrient Intakes for the European Community (CS/RDA 15). Brussels: Commission of the European Communities. Scientific Committee for Food (III/C/I).

COMA (Committee on Medical Aspects of Food Policy) (1991). Dietary Reference Values for Food Energy and Nutrients for the United Kingdom; Report on Health and Social Subjects 41. London: HMSO.

Cook, J. D., Dassenko, S. A. \& Whittaker, P. (1991). Calcium supplementation: effect on iron absorption. American Journal of Clinical Nutrition 53, 106-111.

Crofton, R. W., Gvozdanovic D., Gvozdanovic S, Khin C. C., Brunt, P. W., Mowat, N. A. G. \& Aggett, P. J. (1989). Inorganic zinc and the intestinal absorption of ferrous iron. American Journal of Clinical Nutrition 50, 141-144. 
Davidsson, L., Kastenmayer, P. \& Hurrell, R. F. (1994). Sodium iron EDTA [NaFe (111) EDTA] as a food fortificant: the effect on the absorption and retention of zinc and calcium in women. American Journal of Clinical Nutrition 60 , 231-237.

De Boland, A. R, Garner, G. B. \& O'Dell, B. L. (1975). Identification and properties of "phytate" in cereal grains and oil-seed products. Joumal of Agricultural and Food Chemistry 23, 1186-1189.

Desrosiers, T., \& Clydesdale, F.M. (1989). Effectiveness of organic chelators in solubilizing calcium and zinc in fortified cereals under simulated gastrointestinal pH conditions. Journal of Food Processing and Preservation 13, 307-319.

Fischer, P. W. F., Giroux, A. \& L'Abbé, M. R. (1984). Effect of zinc supplementation on copper status in adult men. American Journal of Clinical Nutrition 40, 743-746.

FitzGerald, S. (1997). Fortification Rapid Assessment Guidelines \& Tool (FRAT). Ottawa: Path Canada.

FAO/WHO (1988). Requirements of Vitamin A, Iron, Folate and Vitamin B $12 ;$ FAO Nutrition Series No. 23. Rome: Food and Agricultural Organization of the United Nations.

FAO/WHO (1993). Joint FAO/WHO Expert Committee on Food Additives 41st report; WHO Technical Report Series 837. Geneva: World Health Organization.

Fosmire, G. J. (1990). Zinc toxicity. American Journal of Clinical Nutrition 51, 225-227.

Freeland-Graves, J. H., Friedman, B. J., Han, W.-H., Shorey, R. L. \& Young, R. (1982). Effect of zinc supplementation on plasma high-density lipoprotein cholesterol and zinc. American Journal of Clinical Nutrition 35, 988-992.

Galloway, R. \& McGuire, J. (1994). Determinants of compliance with iron supplementation: supplies, side effects, and psychology? Social Science \& Medicine 39, 381-390.

Gibson, R. S. (1994). Zinc nutrition in developing countries. Nutrition Research Reviews 7, 151-173.

Gibson, R. S., Koepf, J., Bettger, W. J., Lehrfeld, J. \& Ferguson, E. L. (1997). Dietary strategies to combat trace mineral deficiencies in weanlings from Subsaharan Africa. In Proceedings of the Ninth International Symposium on Trace Elements in Man and Animals, pp. 451-454 [P.W.F. Fischer, M.R.L. L'Abbé, K.A. Cockell and R.S. Gibson, editors]. Ottawa: NRC Research Press.

Gibson, R. S., Smit Vanderkooy, P. D., MacDonald, A. C., Goldman, A., Ryan, B. A \& Berry, M. 1989. A growthlimiting, mild zinc-deficiency syndrome in some Southern Ontario boys with low height percentiles. American Journal of Clinical Nutrition 49, 1266-1273.

Gillespie, S., Kevany, J. \& Mason, J. (1991). Controlling Iron Deficiency; ACC/SCN State-of-the-Art Series Nutrition Policy Discussion Paper No. 9. Geneva: United Nations Administrative Committee on Coordination/Subcommittee on Nutrition.

Golden, M. H. N., Briend, A. \& Grellety, Y. (1995). Meeting Report: Report of meeting on supplementary feeding prgrammes with particular reference to refugee populations. European Journal of Clinical Nutrition 49, 137145.

Goldenberg, R. L., Tamura, T., Neggers, Y., Copper, R. L., Johnston, K., DuBard, M. B. \& Hauth, J. C. (1995). The effect of zinc supplementation on pregnancy outcome. JAMA (Journal of the American Medical Association) 274, $463-468$.

Gopaldas, T., Mehta, P., Patil, A. \& Gandhi, H. (1986). Studies on reduction in viscosity of thick rice gruels with small quantities of an amylase-rich cereal malt. Food and Nutrition Bulletin 8, 42-47.

Graham, R. D., Ascher, J. S. \& Hynes, S. C. (1992). Selecting zinc-efficient cereal genotypes for soils of low zinc status. Plant and Soil 146, 241-250.

Hallberg, L. (1992). Iron balance in pregnancy and lactation. In Nutritional Anaemias, Nestlé Nutrition Workshop Series 30, pp. 13-28 [A. J. Fomon, and S. Zlotkin, editors]. Vevey: Nestlé Ltd.

Hambidge, K. M. (1997). Zinc deficiency in young children. American Journal of Clinical Nutrition 65, $160-161$.

Henderson, L. M., Brewer, G. J., Dressman, J. B., Swidan, S. Z., DuRoss, D. J., Adair, C. H., Barnett, J. L. \& Berardi, R. R. (1995). Effect of intragastric pH on the absorption of oral zinc acetate and zinc oxide in young healthy volunteers. Journal of Parenteral and Enteral Nutrition 19, 393-397.

Hooper, P. L., Visconti, L., Garry, P. J. \& Johnson, G. E. (1980). Zinc lowers high-density lipoprotein-cholesterol levels. Joumal of the American Medical Association 244, 1960-1961.

House, W. A., Van Campen, D. R. \& Welch, R. M. (1996). Influence of dietary sulfur-containing amino acids on the bioavailability to rats of zinc in corn kernels. Nutrition Research 16, 225-235.

Hurrell, R. F. (1997). Preventing iron deficiency through food fortification. Nutrition Reviews 55, $210-222$.

INACG (1993). Iron EDTA for Food Fortification; a Report of the International Nutritional Anemia Consultative Group. Washington, DC: The Nutrition Foundation/ILSI.

ISGPD (International Study Group on Persistent Diarrhea) (1996). Evaluation of an algorithm for the treatment of diarrhea: a multi-centre study. Bulletin of the World Health Organization 74, 479-488.

Lehrfeld, J. (1989). High-performance liquid chromatography analysis of phytic acid on a pH-stable, macroporous polymer column. Cereal Chemistry 66, 510-515.

Lolas, G.M. \& Markakis, P. (1977). The phytase content of navy beans (Phaseolus vulgaris). Journal of Food Science 42, 1094-1097.

Lönnerdal, B., Sandberg A-S., Sandström, B. \& Kunz, C. (1989). Inhibitory effects of phytic acid and other inositol phosphates on zinc and calcium absorption in suckling rats. Journal of Nutrition 119, 211-214.

Lorenz, K. (1980). Cereal sprouts: composition, nutritive value, food applications. Critical Reviews in Food Science and Nutrition 13, 353-385. 
Lotfi, M., Mannar, V., Merx, R. J. H. M. \& Naber-van den Heuvel, P. (1996). Micronutrient Fortification of Foods. Current Practices, Research, and Opportunities. The Micronutrient Initiative, $\mathrm{c} / \mathrm{o}$ International Development Research Centre/International Agriculture Centre.

Mensah, P. P. A., Drasar, B. S., Harrison, T. J. \& Tomkins, A. M. (1991). Fermented cereal gruels: towards a solution of the weanling's dilemma. Food and Nutrition Bulletin 13, 50-57.

Momciloviç, B. (1995). Coupling of zinc dose to frequency in a regularly recurrent pattern shows a limited capacity of excessive dietary zinc to compensate for a previously deficient intake. Journal of Nutrition 125, 2687-2699.

Mosha, A. C. \& Svanberg, U. (1990). The acceptance and intake of bulk-reduced weaning foods: the Luganga village study. Food and Nutrition Bulletin 12, 69-74.

NAS (National Academy of Sciences). (1991). Nutrition during Lactation. Washington, DC: National Academy Press.

Nout, M. J. R. (1993). Processed weaning foods for tropical climates. International Journal of Food Sciences and Nutrition 43, 213-221.

O'Dell, B. L., de Bowland, A. R. \& Koirtyohann, S. R. (1972). Distribution of phytate and nutritionally important elements among the morphological components of cereal grains. Journal of Agricultural and Food Chemistry 20 , 718-721.

Oelshlegel, F. J. \& Brewer, G. J. (1977). Absorption of pharmacological doses of zinc. In Zinc Metabolism: Current Aspects in Health and Disease, pp. 299-316 [G.J. Brewer and A.S. Prasad, editors]. New York: Alan R. Liss.

Prasad, A. S., Beck, F. W. J. \& Nowak, J. (1993). Comparison of absorption of five zinc preparations in humans using oral zinc tolerance test. Joumal of Trace Elements and Electrolytes in Health and Disease 6, 109-115.

Prasad, A. S., Brewer, G. J., Schoomaker, E. B. \& Rabbani, P. (1978). Hypocupremia induced by zinc therapy in adults. Journal of the American Medical Association 240, 2166-2168.

Prasad, A. S., Miale, A., Farid, Z., Sandstead, H. H. \& Schulert, A. R. (1963). Zinc metabolism in patients with syndrome of iron deficiency anemia, hepatosplenomegaly, dwarfism, and hypogonadism. Joumal of Laboratory and Clinical Medicine 61, 537-549.

Rosado, J. L., López, P., Muñoz, E,, Martinez, H. \& Allen, L. H. (1997). Zinc supplementation reduced morbidity, but neither zinc nor iron supplementation affected growth or body composition of Mexican preschoolers. American Journal of Clinical Nutrition 65, 13-19.

Rosado, J. L., Muñoz, E., López, P. \& Allen, L. H. (1993). Absorption of zinc sulfate, methionine, and polyascorbate in the presence and absence of a plant-based rural Mexican diet. Nutrition Research 13, 1141-1151.

Roy, S. K., Behrens, R. H., Haider, R., Akramuzzaman, S. M., Mahalanabis, D., Wahed, M. A. \& Tomkins, A. M. (1992). Impact of zinc supplementation on intestinal permeability in Bangladeshi children with acute diarrhoea and persistent diarrhoea syndrome. Joumal of Pediatric Gastroenterology and Nutrition 15, 289-296.

Sachdev, H. P. S., Mittal, N. K \& Yadav, H. S. (1990). Oral zinc supplementation in persistent diarrhoea in infants. Annals of Tropical Paediatrics 10, 63-69.

Sandberg A-S. \& Andersson, H. (1988). Effect of dietary phytase on the digestion of phytate in the stomach and small intestine of humans. Journal of Nutrition 118, 469-473.

Sandberg A-S, Rossander Hulthen, L. \& Turk, M. (1996). Dietary Aspergillus niger phytase increases iron absorption in humans. Journal of Nutrition 126, 476-480.

Sandström, B., Almgren, A., Kivistö, B. \& Cederblad, Å. (1989). Effect of protein level and protein source on zinc absorption in humans. Journal of Nutrition 119, 48-53.

Sandström, B., Arvidsson, B., Cederblad, Å. \& Björn-Rasmussen, E. (1980). Zinc absorption from composite meals. 1. The significance of wheat extraction rate, zinc, calcium, and protein content in meals based on bread. American Journal of Clinical Nutrition 33, 739-745.

Sandström, B., Davidson, L., Cederblad, A. \& Lönnerdal B. (1985). Oral iron, dietary ligands and zinc absorption. Journal of Nutrition 115, $411-414$.

Sazawal, S., Black, R. E., Bhan, M. K., Bhandari, N., Sinha, A. \& Jalla, S. (1995). Zinc supplementation in young children with acute diarrhea in India. New England Joumal of Medicine 333, 839-844.

Schölmerich, J., Freudemann, A., Köttgen, E., Wietholz, H., Steiert, B., Löhle, B., Häussinger, D. \& Gerok, W. (1987). Bioavailability of zinc from zinc-histidine complexes. 1. Comparison with zinc sulfate in healthy men. American Journal of Clinical Nutrition 45, 1480-1486.

Scott, M. L. \& Zeigler, T. R. (1963). Evidence for natural chelates which aid in the utilization of zinc by chicks. Journal of Agricultural and Food Chemistry 11, 123-125.

Smith, C. J. (1994). Comparison of reference dose with recommended dietary allowances for zinc: methodologies and levels. In Risk Assessment of Essential Elements, pp. 127-143 [W. Mertz, C. O. Abernathy and S. S. Olin, editors]. Washington, DC: ILSI Press.

Snedeker, S. M. \& Greger, J. L. (1983). Metabolism of zinc, copper, and iron as affected by dietary protein, cysteine and histidine. Journal of Nutrition 113, 644-652.

Solomons, N. W. (1986). Competitive interaction of iron and zinc in the diet: consequences for human nutrition. Journal of Nutrition 116, 927-935.

Stoltzfus, R. J., Dreyfuss, M. L., Chwaya, H. M. \& Albonico, M. (1997). Hookworm control as a strategy to prevent iron deficiency. Nutrition Reviews 55, 223-232.

Sturniolo, G. C., Montino, C., Rossetto, L., Martin, A., D'Inca, R., D'Odorico, A. \& Naccarato, R. (1991). Inhibition of gastric acid secretion reduces zinc absorption in man. Journal of the American College of Nutrition 10, 372375 . 
Svanberg, U. \& Sandberg, A-S. (1988). Improved iron availability in weaning foods through the use of germination and fermentation. In Improving Young Child Feeding in Eastem and Southern Africa; Household Level Food Technology, pp. 366-373 [D. Alnwick, S. Moses and O.G. Schmidt, editors]. Nairobi: International Development Research Center.

Svanberg, U., Lorri, W. \& Sandberg, A-S. (1993). Lactic fermentation of non-tannin and high-tannin cereals: effects on in vitro estimation of iron availability and phytate hydrolysis. Journal of Food Science 58, 408-412.

Swanson, C. A. \& King, J. C. (1987). Zinc and pregnancy outcome. American Journal of Clinical Nutrition 46, 763771.

Tabekhia, M. M. \& Luh, B. S. (1980). Effect of germination, cooking, and canning on phosphorus and phytate retention in dry beans. Journal of Food Science 45, 406-408.

Tamura. T. \& Goldenberg, R. L. (1996). Zinc nutriture and pregnancy outcome. Nutrition Research 16, $139-181$.

Tomkins, A., Behrens, R. \& Roy, S. (1993). The role of zinc and vitamin A deficiency in diarrhoeal syndromes in developing countries. Proceedings of the Nutrition Society 52, 131-142.

Turk, M. \& Sandberg, A.-S. (1992). Phytate degradation during breadmaking: effect of phytase addition. Journal of Cereal Science 15, 281-294.

Udomkesmalee, E., Dhanamitta, S., Yhoung-Aree, J., Rojroongwasinkul, N. \& Smith, J. C. (1990). Biochemical evidence suggestive of suboptimal zinc and vitamin A status in schoolchildren in Northeast Thailand. American Journal of Clinical Nutrition 52, 564-567.

U.S. EPA (Environmental Protection Agency) (1992). Reference dose (Rfd): description and use in health risk assessments, IRIS, online. Cincinnati, $\mathrm{OH}$ : Environmental Criteria and Assessment Office,.

United Nations (1991). Some options for improving nutrition in the 1990s. SCN News no. 7, Suppl. 16-18.

Valberg, L. S., Flanagan, P. R. \& Chamberlain, M. J. (1984). Effects of iron, tin and copper on zinc absorption in humans. American Journal of Clinical Nutrition 40, 536-541.

Viteri, F. E., Alvarez, E., Batres, R., Torún, B., Pineda, O., Mejía, L. A. \& Sylvi, J. (1995). Fortification of sugar with iron sodium ethylenedaminotetraacetate (FeNaEDTA) improves iron status in semirural Guatemalan populations. American Joumal of Clinical Nutrition 61, 1153-1163.

Walsh, C. T., Sandstead, H. H., Prasad, A. S., Newberne, P. M. \& Fraker, P. J. (1994). Zinc: health effects and research priorities for the 1990s. Environmental Health Perspectives 102 (Suppl. 2), 5-46.

Wedekind, K. J. \& Baker, D. H. (1990). Zinc bioavailability in feed-grade sources of zinc. Journal of Animal Science 68, 684-689.

Williams, G. \& Naraqi, S. (1979). Severe anaemia in Port Moresby. A review of 101 adult melanesian patients with haemoglobin level of $4 \mathrm{~g} / 100 \mathrm{ml}$ or less. Papua New Guinea Medical Journal 22, 129-136.

Wolfe, S. A., Gibson, R. S., Gadowsky, S. L. \& O'Connor, D. L. (1994). Zinc status of a group of pregnant adolescents at 36-weeks gestation living in Southern Ontario. Joumal of the American College of Nutrition 13, 154-164.

Wood, R. J. \& Zheng, J. J. (1997). High dietary calcium intakes reduce zinc absorption and balance in humans. American Journal of Clinical Nutrition 65, 1803-1809.

WHO (1996). Trace Elements in Human Nutrition and Health. Geneva: World Health Organization.

Xu, P., Price, J. \& Aggett, P. J. (1992). Recent advances in methodology for analysis of phytate and inositol phosphates in foods. Progress in Food and Nutrition Science 16, 245-262.

Yadrick, M. K., Kenney, M. A \& Winterfeldt, E. A. (1989). Iron, copper and zinc status: response to supplementation with zinc or zinc and iron in adult females. American Journal of Clinical Nutrition 49, 145-150. 